\title{
Pengaruh Customer Relationship Management Terhadap Keunggulan Bersaing Dalam Meningkatkan Kinerja Pemasaran Usaha Kecil Industri Makanan Di Bakorwil II Jawa Timur
}

\author{
Marwita Andarini ${ }^{1}$, Nur Laely ${ }^{2}$ \\ 1,2Fakultas Ekonomi Universitas Kadiri \\ email: ${ }^{1}$ marwita_andarini@unik-kediri.ac.id, ${ }^{2}$ uurlaely@unik-kediri.ac.id,
}

Kata kunci: [Heading kata kunci] customer relationship management, keunggulan bersaing, kinerja pemasaran

Keywords: [heading kata kunci] customer relationship management, competitive advantage, marketing performance

Marwita Andarini \& Nur Laely (2019). Pengaruh Customer Relationship Management Terhadap Keunggulan Bersaing Dalam Meningkatkan Kinerja Pemasaran Usaha Kecil Industri Makanan Di Bakorwil II Jawa Timur. Akuntabilitas: Jurnal Ilmiah Ilmu-Ilmu Ekonomi, 12(2), 23 $-41$.

\begin{abstract}
ABSTRAK
Kegiatan pemasaran akan berhubungan erat dengan adanya program Customer Relationship Management dikarenakan memiliki kaitan dengan peningkatan Kinerja Pemasaran melalui pengaruh secara langsung maupun tidak langsung pada keunggulan bersaing. Tujuan penelitian ini yaitu untuk mengetahui bagaimana pengaruh customer relationship management terhadap keunggulan bersaing dalam meningkatkan kinerja pemasaran yang dilakukan melalui pengolahan data uji path analysis menggunakan SPSS IBM 23 menggunakan pengambilan populasi dengam sampel 96 responden menggunakan formula Lemeshow, dilakukan uji validitas dan reliabilitas untuk mengetahui atribut- atribut yang memiliki kevalidan data dengan asumsi $R_{h i t u n g}>R_{\text {tabel }}$ yaitu $P_{\text {value }}>$ 0.1986, sedangkan pada tingkat reliabel didaptakan nilai cronbach alpha sebesar 0,812 yang sangat reliabel, kemudian dilakukan uji regresi untuk mengambil model summary dan koefisien untuk digunakan dalam path analysis, didapatkan hasil bahwa pengaruh langsung memiliki nilai sebesar 54,3\% sedangkan pengaruh tidak langsung lebih kecil yaitu sebesar $0,088 \%$. Pada atribut memberi pengaruh secara langsung lebih besar dari pada pengaruh tidak langsung melalui keunggulan bersaing terhadap kinerja pemasaran usaha kecil industri makanan di Bakorwil II Jawa Timur.
\end{abstract}

\section{ABSTRACT}

Marketing activities will be closely related to the Customer Relationship Management program because it has a relationship with increasing Marketing Performance through direct or indirect influence on competitive advantage. The purpose of this study is to determine how the influence of customer relationship management on competitive advantage in improving marketing performance is done through data processing test path analysis using SPSS IBM 23 using population sampling with a sample of 96 respondents using the Lemeshow formula, carried out validity and reliability tests to determine the attributes of attributes that have validity of data with the assumption of Rhitung $>$ Rtable that is Pvalue > 0.1986, while at a reliable level the Cronbach alpha value of 0.812 is very reliable, then a regression test is carried out to take a summary model and coefficients to be used in the path analysis, the results show that the direct effect has a value of $54.3 \%$ while the indirect effect is smaller at $0.088 \%$. The attribute gives a direct influence is greater than the indirect effect through competitive advantage on the marketing performance of the food industry small business in Bakorwil II East Java.

\footnotetext{
Pengaruh Customer Relationship Management Terhadap Keunggulan Bersaing Dalam Meningkatkan Kinerja Pemasaran Usaha Kecil Industri Makanan Di Bakorwil II Jawa Timur 


\section{PENDAHULUAN}

Munculnya persaingan dalam dunia bisnis merupakan hal yang tidak dapat dihindari, dengan adanya persaingan, maka perusahaan - perusahaan dihadapkan pada berbagai peluang dan ancaman baik yang berasal dari luar maupun dari dalam negeri. Setiap perusahaan dituntut untuk selalu mengerti dan memahami apa yang terjadi di pasar dan apa yang menjadi keinginan konsumen, serta berbagai perubahan yang ada di lingkungan bisnisnya sehingga mampu bersaing dengan perusahaan-perusahaan lainnya. Sudah seharusnya perusahaan berupaya untuk meminimalisasi kelemahan-kelemahannya dan memaksimalkan kekuatan yang dimilikinya. Dalam lingkup pemasaran dalam usaha mikro memang dikatakan masih dalam tahap perkembangan dikarenakan mayoritas usaha mikro yang berdiri adalah milik rumah tangga ataupun keluarga. Kegiatan yang menimbulkan efek timbal balik yang bagus dengan ciri kesetiaan dan komitmen pelanggan agar tetap menggunakan kan perusaahaan yang bersangkutan serta data- data pelanggan mampu direkam, dilindungi oleh perusahaan agar tidak diketahui oleh kompetitor yang ingin membuat produk yang sama. Mempelajari pelanggan diperlukan oleh perusahaan agar dapat menciptakan model cara berbisnis yang diinginkan pelanggan serta cara adaptasi yang mampu memberikan perubahan kondisi pasar.

Kinerja pemasaran akan meningkat atau menurun jika faktor dalam apa yang diinginkan oleh konsumen mampu atau tidaknya diketahui oleh perusahaan, mampu tidaknya data- data terkait privasi pelanggan direkam sebagai data otentik untuk mengetahui selera konsumen dalam menggunakan produk dan faktor yang mampu konsisten terhadap munculnya produk sebagai fokus utama karena mampu memberi pengaruh kebutuhan- kebutuhan konsumen. Dari hal tersebut, maka munculah pemikiran bahwa dalam kinerja pemasaran apakah memiliki pengaruh terhadap adanya customer relationship management dengan keunggulan bersaing. Karena didalam keunggulan bersaing sebuah produk akan mampu bersaing jika program customer relationship management mampu dipahami perusahaan serta jika saling memberi pengaruh besar dan pengaruh langsung akan meningkatkan kinerja pemasaran. 
Tujuan penelitian ini untuk menganalisis pengaruh customer relationship management terhadap keunggulan bersaing dalam meningkatkan kinerja pemasaran.

\section{METODE PENELITIAN}

\section{Jenis Penelitian}

Dalam penelitian ini memiliki jenis penelitian kuantitatif dikarenakan memiliki variabel dependen dan variabel independen dengan penambahan variabel antara (intervening). Dalam variabel antara (intervening) memiliki fungsi sebagai melemahkan ataupun memperkuat hubungan antara variabel, tetapi tidak mampu diukur dan tidak dapat dilakukan pengamatan karena terletak antara variabel independen dan dependen. Menurut (Holmbeck, 1997) dikatakan bahwa variabel intervening yang akan menentukan mekanisme terhadap efek yang diberikan antara variabel dependen dan variabel independen.

\section{Tempat Penelitian}

Lokasi penelitian ini adalah usaha kecil industri makanan di Bakorwil II Jawa Timur.

\section{Populasi dan Sampel}

Populasi yang diambil dengan menggunakan rumus Lemeshow dikarenakan tidak diketahui jumlah populasinya, maka pengambilan sampel minimul untuk digunakan dalam penelitian dapat diketahui dengan rumus sebagai berikut (Safi'i, 2018) :

$$
n=\frac{s^{2} x A(1-A)}{b^{2}}
$$

Keterangan :

$$
\begin{array}{ll}
\mathrm{n} & \text { : Jumlah sampel } \\
\mathrm{S} & \text { : Tingkat kepercayaan } 95 \%=1,96 \\
\mathrm{~A} & \text { : Estimasi maksimal }=0,5 \\
\mathrm{~b} & \text { : kesalahan sampel }=10 \%
\end{array}
$$

Dalam perhitungan sampel menggunakan rumus diatas, maka didapat jumlah sampel n sebesar 96,04 yang dibulatkan menjadi 96 responden. Maka, sampel minimum yang digunakan adalah 96 responden. 


\section{Metode Pengumpulan Data}

Melakukan pengumpulan data informasi melalui wawancara dan pengisian angket kepada pedagang yang berjumlah 96 responden di wilayah Bakorwil II Jawa Timur. Pengisian kusioner menyangkut tema penelitian yaitu tentang pengaruh customer relationship management terhadap keunggulan bersaing dalam meningkatkan kinerja pemasaran usaha kecil industri makanan di Bakorwil II Jawa Timur.

\section{Metode Analisa}

Dalam metode analisa data dilakukan beberapa tahapan sebagai berikut :

1. Analisis Deskriptif berfungsi sebagai penyimpulan dari data mentah dalam jumlah yang besar.

2. Uji Validitas pada data jika valid bernilai $R_{\text {hitung }}>R_{\text {tabel }}$ dan Uji Reliabilitas pada data jika reliabel pada Cronbach Alpha bernilai 0,6 (Salim, Sudharma, Kusumaratna, \& Hidayat, 2016). Nilai 0,05 sebagai tingkat signifikasi dalam pengolahan data mentah yang akan diolah menggunakan software SPSS IBM 23.

3. Analisis Regresi Model I dan Analisis Regresi Model II digunakan untuk pengambilan pengolahan data yaitu pengambilan tabel model summary dan tabel koefisien yang akan digunakan untuk melakukan tahap mengetahui apakah variabel interventing dapat memberikan pengaruh secara langsung atau tidaknya terhadap variabel dependen dan variabel independen.

4. Path Analysis bertujuan sebagai cara mengetahui apakah variabel dependen dan variabel independen memiliki pengaruh secara langsung maupun tidak langsung terhadap variabel intervening. Variabel dependen yaitu kinerja pemasaran, variabel independen yaitu customer relationship management dan variabel intervening adalah keunggulan bersaing (Hermuningsih, 2012). Untuk memperjelas konsep dari path analysis pada gambar dibawah ini :

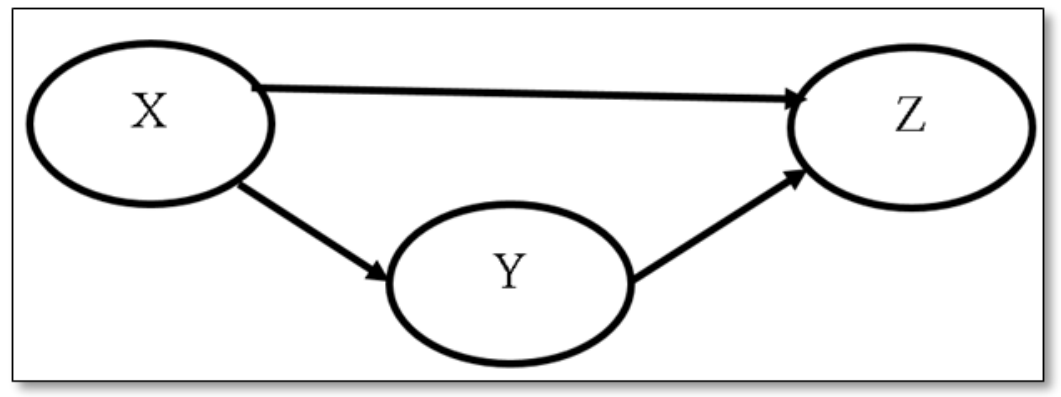

Gambar 1 Kerangka Pemikiran Path Analysis 
Berdasarkan gambar diatas, perumusan hipotesis yang akan digunakan yaitu dilakukan pengujian secara satu persatu sebagai berikut :
a. Pengaruh $\mathrm{X}$ terhadap $\mathrm{Y}$, jika nilai $\mathrm{X}<0,05$ dinyatakan signifikan.
b. Pengaruh $X$ terhadap $Z$, jika nilai $X<0,05$ dinyatakan signifikan.
c. Pengaruh $\mathrm{Y}$ terhadap $\mathrm{Z}$, jika nilai $\mathrm{Y}<0,05$ dinyatakan signifikan.
d. Pengaruh $X$ melalui $Y$ terhadap $Z$

Dalam tahap path analysis, akan digunakan tabel model summary dan tabel coefficients untuk menghitung koefisien jalur dan uji hipotesis tersebut untuk memberikan kesimpulan. Kemudian untuk mengetahui nilai $e$ digunakan formula sebagai berikut(Riduwan \& Kuncoro, 2008) :

$$
e 1=\sqrt{(1-\text { nilai } R \text { Square }}
$$

Nilai $e$ merupakan variabel dependen pada model regresi I dan model regresi II.

\section{PEMBAHASAN}

\section{Analisis Deskriptif}

Tabel 1Analisis Deskriptif

\begin{tabular}{|c|c|c|c|c|c|}
\hline & $\mathrm{N}$ & $\begin{array}{l}\text { Minimu } \\
\mathrm{m}\end{array}$ & $\begin{array}{l}\text { Maximu } \\
\mathrm{m}\end{array}$ & Mean & $\begin{array}{l}\text { Std. } \\
\text { Deviati } \\
\text { on }\end{array}$ \\
\hline $\begin{array}{lr}\text { Perusahaan } & \text { mampu } \\
\text { dengan cepat } & \text { melayani } \\
\text { pelanggan } & \text { secara } \\
\text { individual } & \end{array}$ & 96 & 1 & 5 & 4.44 & 1.044 \\
\hline $\begin{array}{lr}\text { Perusahaan } & \text { mampu } \\
\text { menangani } & \text { keluhan dari } \\
\text { pelanggan } & \text { secara } \\
\text { individual } & \end{array}$ & 96 & 1 & 5 & 4.46 & 1.035 \\
\hline $\begin{array}{l}\text { Perusahaan memberikan } \\
\text { kartu ucapan pada saat } \\
\text { moment spesial kepada } \\
\text { setiap pelanggan }\end{array}$ & 96 & 1 & 5 & 4.45 & 1.045 \\
\hline \begin{tabular}{lr} 
Perusahaan & mampu \\
menjual & \multicolumn{2}{c}{ dengan } \\
keunggulan & harga yang \\
lebih murah &
\end{tabular} & 96 & 1 & 5 & 4.46 & .962 \\
\hline
\end{tabular}

Pengaruh Customer Relationship Management Terhadap Keunggulan Bersaing Dalam Meningkatkan Kinerja Pemasaran 


\begin{tabular}{llllll}
\hline $\begin{array}{l}\text { Perusahaan memiliki } \\
\text { target jumlah total }\end{array}$ & & & & & \\
penjualan lebih besar & 96 & 1 & 5 & 4.29 & 1.187 \\
dibandingkan periode \\
tahun sebelumnya
\end{tabular}

Pada tabel 1 , analisis deskriptif jumlah responden $(n)=96$ dari responden inilah yang memilih nilai angket minimal (Sangat tidak setuju) bernilai 1 sedangkan nilai angket maksimal (sangat setuju) bernilai 5 dengan nilai rata- rata dari responden yang mengisi kuisioner tentang Pengaruh Customer Relationship Management Terhadap Keunggulan Bersaing Dalam Meningkatkan Kinerja Pemasaran Usaha Kecil Industri Makanan Di Bakorwil II Jawa Timur pada (X1.1) Perusahaan mampu dengan cepat melayani pelanggan secara individual $=4.44$, (X1.2) Perusahaan mampu menangani keluhan dari pelanggan secara individual=4.46, (X1.3) Perusahaan memberikan kartu ucapan pada saat moment spesial kepada setiap pelanggan $=4.45$, (Y) Perusahaan mampu menjual dengan keunggulan harga yang lebih murah $=4.46$ dan atribut $(Z)$ Perusahaan memiliki target jumlah total penjualan lebih besar dibandingkan periode tahun sebelumnya $=4.29$. Dalam pengisian angket dirasa sangat cukup untuk harapan dari pengisian angketnya.

\section{Uji Validitas}

Tabel 2 Uji Validitas

\begin{tabular}{ccccc}
\hline No. & Atribut & $R_{\text {tabel }}$ & \multicolumn{1}{c}{ R hitung } & Kesimpulan \\
\hline 1 & $\mathrm{X} 1.1$ & 0.1986 & 0,669 & Valid \\
\hline 2 & $\mathrm{X} 1.2$ & 0.1986 & 0,404 & Valid \\
\hline 3 & $\mathrm{X} 1.3$ & 0.1986 & 0,505 & Valid \\
\hline 4 & $\mathrm{Y}$ & 0.1986 & 0,361 & Valid \\
\hline
\end{tabular}

Pada tabel 1 dilakukan uji validitas pada atribut- atribut yang digunakan dengan asumsi data valid jika nilai $R_{\text {hitung }}>R_{\text {tabel }}$ dan jika valid maka atribut- atribut 
tersebut bisa dinyatakan sebagai alat ukur atribut untuk dilakukan pengolahan data selanjunya.

\section{Uji Reliabilitas}

Tabel 3 Uji Reliabilitas

\begin{tabular}{cc}
\hline $\begin{array}{c}\text { Cronbach's } \\
\text { Alpha }\end{array}$ & $\begin{array}{c}\mathrm{N} \text { of } \\
\text { Items }\end{array}$ \\
\hline .812 & 5
\end{tabular}

Dalam perhitungan reliabilitas dalam atribut- atribut yang digunakan dimaksudkan untuk mengetahui jawaban responden dari pengisian angket yang sudah diberikan terhadap pertanyaan yang ada diangket tersebut. Uji reliabilitas berguna untuk mengidentifikasi pertanyaan yang mampu digunakan dari waktu ke waktu dan memiliki nilai Cronbach alpha > 0.6 maka, dapat dinyatakan reliabel.

\section{Regresi Model I}

Tabel 4Model Summary

\begin{tabular}{lllll}
\hline $\begin{array}{l}\text { Mode } \\
1\end{array}$ & $\mathrm{R}$ & R Square & $\begin{array}{l}\text { Adjusted } \\
\text { Square }\end{array}$ & $\begin{array}{c}\text { R Std. Error of } \\
\text { the Estimate }\end{array}$ \\
\hline 1 & $.514^{\mathrm{a}}$ & .264 & .240 & .838 \\
\hline
\end{tabular}

a. Predictors: (Constant), Perusahaan memberikan kartu ucapan pada saat moment spesial kepada setiap pelanggan, Perusahaan mampu menangani keluhan dari pelanggan secara individual, Perusahaan mampu dengan cepat melayani pelanggan secara individual

Pada tabel 4 dikatakan bahwa nilai $\mathrm{R}$ merupakan korelasi dari variabel $\mathrm{X}$ terhadap Y dengan nilai 0,514 dinyatakan berkorelasi. R Square sebesar 0,264 yang berarti pemberian pengaruh (X1.1), (X1.2) dan (X1.3) sebesar 26,4\% dan jika dihitung secara $100 \%$ maka sisanya sebesar $73,6 \%$ yang merupakan kontribusi dari atribut yang lain karena tidak dimasukkan kedalam penelitian ini. Kemudian pada standard Error of the Estimate merupakan estimasi kesalahan variabel (Y) Perusahaan mampu menjual dengan keunggulan harga yang lebih murah dengan tingkat kesalahan Pengaruh Customer Relationship Management Terhadap Keunggulan Bersaing Dalam Meningkatkan Kinerja Pemasaran Usaha Kecil Industri Makanan Di Bakorwil II Jawa Timur 
sebesar 0,838 satuan, sedangkan pada Adjusted R Square merupakan koefisien determnasi yang sudah dikoreksi pada jumlah variabel dan ukuran sampel yang digunakan sehingga variasi pada variabel (Y) sebesar 0,240 satuan.

Tabel 5 Coefficient

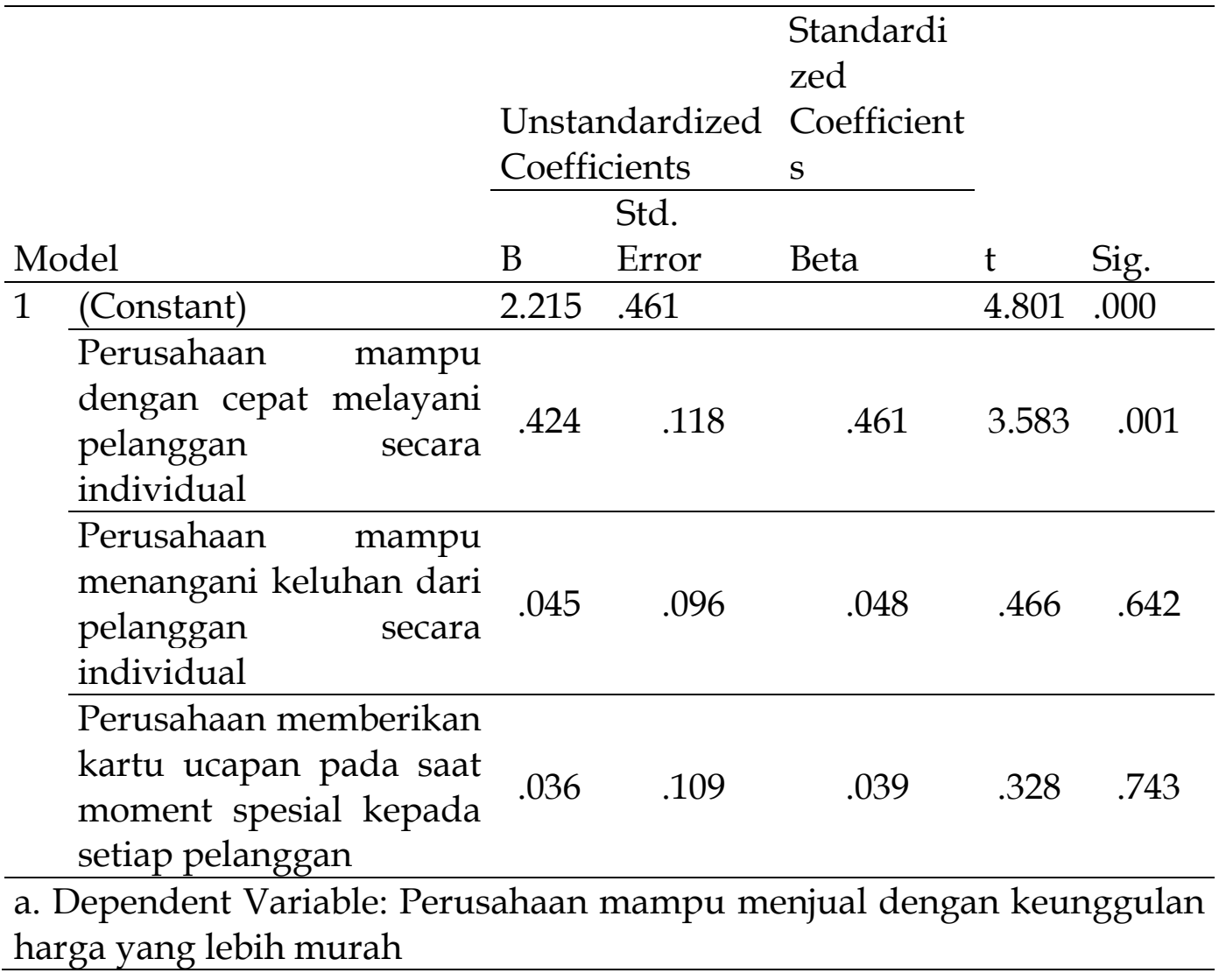

Pada tabel 5 coefficients dikatakan memberikan informasi tentang model regresi linier terhadap ada tidaknya pengaruh variabel $\mathrm{X}$ terhadap $\mathrm{Y}$ dengan model persamaan sebagai berikut :

$\mathrm{Y}=2,215+0,424 \mathrm{X}_{1.1}+0,45 \mathrm{X}_{1.1}+0,36 \mathrm{X}_{1.3}$

Dalam model regresi linier berganda tersebut dinyatakan bahwa koefisien X1.1 bernilai positif yang akan meningkatkan pelayanan sebesar 0,424 satuan dan sebaliknya sedangkan pada X1.2 akan memberikan penanganan keluhan kepada pelanggan sebesar 0,045 satuan dan sebaliknya sedangkan pada X1.3 terjadi pemberian kartu ucapan pada momen spesial dengan pemberian pengaruh sebesar 

pertanyaan yang telah disebutkan.

\section{Regresi Model II}

Tabel 6 Model Summary

\begin{tabular}{ccccc}
\hline $\begin{array}{l}\text { Mode } \\
1\end{array}$ & R & \multicolumn{2}{c}{$\begin{array}{l}\text { Adjusted } \\
\text { R Square }\end{array}$} & $\begin{array}{l}\text { S Std. Error of } \\
\text { the Estimate }\end{array}$ \\
\hline 1 & $.679^{\mathrm{a}}$ & .460 & .437 & .891 \\
\hline
\end{tabular}

a. Predictors: (Constant), Perusahaan mampu menjual dengan keunggulan harga yang lebih murah, Perusahaan mampu menangani keluhan dari pelanggan secara individual, Perusahaan memberikan kartu ucapan pada saat moment spesial kepada setiap pelanggan, Perusahaan mampu dengan cepat melayani pelanggan secara individual

Pada tabel 6 dikatakan bahwa nilai $\mathrm{R}$ merupakan korelasi dari variabel $\mathrm{X}$ terhadap Z melalui $\mathrm{Y}$ dengan nilai 0,679 dinyatakan berkorelasi. R Square sebesar 0,460 yang berarti pemberian pengaruh (X1.1), (X1.2), (X1.3) dan (Y) sebesar 46\% dan jika dihitung secara 100\% maka sisanya sebesar 54\% yang merupakan kontribusi dari atribut yang lain karena tidak dimasukkan kedalam penelitian ini. Kemudian pada standard Error of the Estimate merupakan estimasi kesalahan variabel $(Z)$ sebesar 0,891 satuan, sedangkan pada Adjusted R Square merupakan koefisien determnasi yang sudah dikoreksi pada jumlah variabel dan ukuran sampel yang digunakan sehingga variasi pada variabel $(Z)$ sebesar 0,437 satuan.

Tabel 7 Nilai Koefisien

\begin{tabular}{|c|c|c|c|c|c|}
\hline \multirow[b]{2}{*}{ Model } & $\begin{array}{l}\text { Unst } \\
\mathrm{d} \mathrm{Co}\end{array}$ & $\begin{array}{l}\text { ndardize } \\
\text { fficients }\end{array}$ & $\begin{array}{l}\text { Standardize } \\
\mathrm{d} \\
\text { Coefficients }\end{array}$ & & \\
\hline & B & $\begin{array}{l}\text { Std. } \\
\text { Error }\end{array}$ & Beta & $\mathrm{t}$ & Sig. \\
\hline 1 (Constant) & .453 & .548 & & .826 & .411 \\
\hline
\end{tabular}

Pengaruh Customer Relationship Management Terhadap Keunggulan Bersaing Dalam Meningkatkan Kinerja Pemasaran 


\begin{tabular}{|c|c|c|c|c|c|}
\hline $\begin{array}{l}\text { Perusahaan } \\
\text { mampu dengan } \\
\text { cepat melayani } \\
\text { pelanggan secara } \\
\text { individual }\end{array}$ & .618 & .134 & .543 & 4.596 & .000 \\
\hline $\begin{array}{l}\text { Perusahaan } \\
\text { mampu } \\
\text { menangani } \\
\text { keluhan dari } \\
\text { pelanggan secara } \\
\text { individual }\end{array}$ & .098 & .102 & .086 & .961 & .339 \\
\hline \begin{tabular}{lr}
\multicolumn{2}{l}{ Perusahaan } \\
memberikan \\
kartu & ucapan \\
pada & saat \\
moment & spesial \\
kepada & setiap \\
pelanggan & \\
\end{tabular} & .125 & .116 & .110 & 1.077 & .284 \\
\hline $\begin{array}{l}\text { Perusahaan } \\
\text { mampu menjual } \\
\text { dengan } \\
\text { keunggulan } \\
\text { harga yang lebih } \\
\text { murah }\end{array}$ & .023 & .111 & .019 & .208 & .835 \\
\hline
\end{tabular}

Pada tabel 7 coefficients dikatakan memberikan informasi tentang model regresi linier terhadap ada tidaknya pengaruh variabel $\mathrm{X}$ terhadap $\mathrm{Y}$ dengan model persamaan sebagai berikut :

$Z=0,453+0,618 X_{1.1}+0,98 X_{1.1}+0,125 X_{1.3}+0,023 Y$

Dalam model regresi linier berganda tersebut dinyatakan bahwa koefisien X1.1 bernilai positif yang akan meningkatkan pelayanan sebesar 0,618 satuan dan sebaliknya sedangkan pada X1.2 akan memberikan penanganan keluhan kepada pelanggan sebesar 0,98 satuan dan sebaliknya sedangkan pada X1.3 terjadi pemberian kartu ucapan pada momen spesial dengan pemberian pengaruh sebesar 0,125 satuan dan sebaliknya dan pada Y Perusahaan mampu menjual dengan keunggulan harga yang lebih murah memberikan pengaruh sebesar 0,023 satuan 
dan sebaliknya jika variabel tersebut tidak mampu melakukan sesuai pertanyaan yang telah disebutkan.

\section{Path Analysis}

a. Koefisien Jalur Model I

Pada analisis regresi model I pada tabel coefficient dapat diketahui pada nilai signifikan atribut (X1.1) Perusahaan mampu dengan cepat melayani pelanggan secara individual $=0,001$, kemudian atribut (X1.2) Perusahaan mampu menangani keluhan dari pelanggan secara individual $=0,642$ dan (X1.3) Perusahaan memberikan kartu ucapan pada saat moment spesial kepada setiap pelanggan $=0,743$ jika digunakan asumsi tingkat signifikasi, maka atribut (X1.1) Perusahaan mampu dengan cepat melayani pelanggan secara individual dikatakan memiliki pengaruh yang signifikan terhadap Y (Perusahaan memiliki target jumlah total penjualan lebih besar dibandingkan periode tahun sebelumnya), sedangkan untuk atribut (X1.2) dan (X1.3) dinyatakan tidak signifikan disebabkan nilai Sig. > 0,05. Sedangkan pada tabel model summary diasumsikan pada $\mathrm{R}$ Square sebesar 0,264 yang berarti pemberian pengaruh (X1.1), (X1.2) dan (X1.3) sebesar 26,4\% dan jika dihitung secara 100\% maka sisanya sebesar 73,6\% yang merupakan kontribusi dari atribut yang lain karena tidak dimasukkan kedalam penelitian ini. Kemudian dilakukan perhitungan pada nilai e dengan cara sebagai berikut :

$$
\begin{aligned}
& e 1=\sqrt{(1-0,264} \\
& e 1=0,8579
\end{aligned}
$$

Maka, jalur struktur model I digambarkan sebagai berikut :

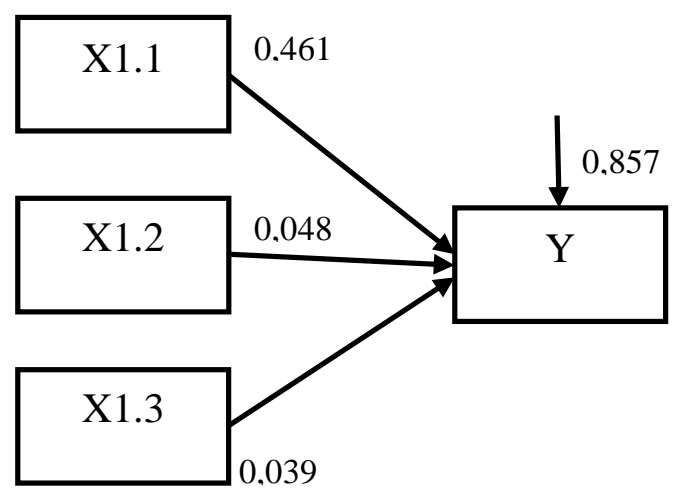

Pengaruh Customer Relationship Management Terhadap Keunggulan Bersaing Dalam Meningkatkan Kinerja Pemasaran 
Gambar 2 Jalur path model I

Nilai dari atribut (X1.1), (X1.2) dan (X1.3) didapat dari tabel coeffficients pada Standardized Coefficients nilai beta.

b. Koefisien Jalur Model II

Pada analisis regresi model II di dalam tabel coefficients diketahui bahwa nilai dari atribut (X1.1) Perusahaan mampu dengan cepat melayani pelanggan secara individual $=0,000$, kemudian atribut (X1.2) Perusahaan mampu menangani keluhan dari pelanggan secara individual =0,339, (X1.3) Perusahaan memberikan kartu ucapan pada saat moment spesial kepada setiap pelanggan $=0,284$ dan $(\mathrm{Y})$ Perusahaan mampu menjual dengan keunggulan harga yang lebih murah =0,835. Maka, dapat diasumsikan bahwa atribut - atribut tersebut yang berpengaruh terhadap variabel hanya pada atribut (X1.1) Perusahaan mampu dengan cepat melayani pelanggan secara individual terhadap atribut Z (Perusahaan memiliki target jumlah total penjualan lebih besar dibandingkan periode tahun sebelumnya). Didalam model summary pada nilai R Square didapatkan sebesar 0,460 yang mampu dijelaskan pada penelitian dan sisanya sebesar 54\% dari prosentase $100 \%$ tidak jelaskan pada penelitian dikarenakan tidak dilakukan penelitian pada atribut tersebut. Kemudian dilakukan perhitungan pada nilai e dengan cara sebagai berikut :

$$
\begin{aligned}
& e 1=\sqrt{(1-0,460} \\
& e 1=0,734
\end{aligned}
$$

Maka, jalur struktur model I digambarkan sebagai berikut : 


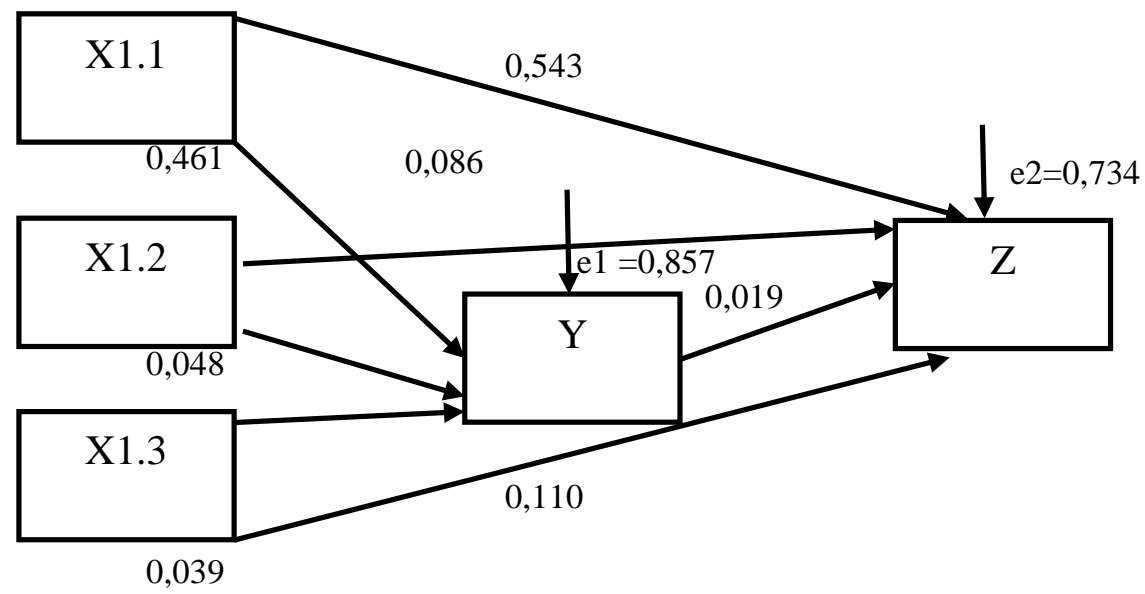

Gambar 3 Jalur Path Model II

Nilai dari atribut (X1.1), (X1.2), (X1.3) dan (Y) didapat dari tabel coeffficients pada Standardized Coefficients nilai beta.

Dalam tahapan uji hipotesis dilakukan dengan analisa pada gambar tersebut dengan hasil uji hipotesis sebagai berikut :

a. Pengaruh $X$ terhadap $Y$, jika nilai $X<0,05$ dinyatakan signifikan hanya pada atribut (X1.1) Perusahaan mampu dengan cepat melayani pelanggan secara individual $=0,001$. Dalam hal ini perusahaan dengan cepat melayani pelanggan dikarenakan sudah memiliki pengalam dibidangnya dan sudah memahami kondisi antrian pelanggan jika saat itu terjadi pembelian produk makanan secara antrian panjang, maka pentingnya pengalaman dalam memberi pelayanan akan berpengaruh signifikan terhadap keunggulan bersaing pada atribut $(\mathrm{Y})$ Perusahaan mampu menjual dengan keunggulan harga yang lebih murah, dikarenakan semakin murahnya produk yang dijual tapi dengan pelayanan yang baik, pelanggan secara tidak langsung akan menyukai produk tersebut dari segi pelayanan dan harga yang diberikan oleh perusahaan karena dalam perhitungan nilai Sig. 0,000 diasumsikan nilai yang sangat signifikan pada cara memberi pelayanan terhadap keunggulan dalam persaingan antara produk sejenisnya. Sedangkan pada atribut (X1.2) Perusahaan mampu menangani keluhan dari pelanggan secara individual $=0,339$ dalam hal ini dinyatakan tidak signifikan 
sebab, keluhan pelanggan yang diajukan mungkin belum sepenuhnya dipahami oleh perusahaan dikarenakan perusahaan dalam menerima keluhan dari pelanggan langsung memberi evaluasi tetapu dalam penerapannya mungkin belum sesuai harapan pelanggan dan (X1.3) Perusahaan memberikan kartu ucapan pada saat moment spesial kepada setiap pelanggan $=0,284$ dalam hal ini dikatakan tidak signifikan sebab, produk makanan yang ditawarkan masih dalam tingkat usaha kecil oleh karena itu pedagang mungkin belum setuju jika ada pemberian kartu ucapan momen dikarenakan laba dari jualan belum ada anggaran untuk membuat souvenir kartu ucapan.

b. Pengaruh $X$ terhadap $Z$, jika nilai $X<0,05$ dinyatakan signifikan hanya pada atribut (X1.1) Perusahaan mampu dengan cepat melayani pelanggan secara individual $=0,001$ karena pedagang sudah berpengalaman dalam memberikan pelayanan kepada pelanggannya dan hal ini akan memberi pengaruh besar terhadap Z (Perusahaan memiliki target jumlah total penjualan lebih besar dibandingkan periode tahun sebelumnya) maka, semakin cepat dan baik pelayanan yang diberikan juga akan semakin besar kesempatan dalam mencapai target penjualan agar lebih besar dari periode tahun sebelumnya. Dikarenakan jika pelayanan yang diberikan pedagang ke pelanggan sangat responsif, pelanggan akan kembali datang untuk membeli produk tersebut. Beda dengan atribut (X1.2) Perusahaan mampu menangani keluhan dari pelanggan secara individual $=0,339$ tidak signifikan dikarenakan keluhan tidak berpotensi terhadap adanya target penjualan, maka penjualan makanan yang saat ini dilakukan hanya berfokus untuk mencapai target tanpa memikirkan secara panjang apa yang dikeluhkan oleh pelanggan. Sedangkan pada (X1.3) Perusahaan memberikan kartu ucapan pada saat moment spesial kepada setiap pelanggan $=0,284$ hal ini tidak memberi pengaruh sebab akan berpotensi mengurangi biaya bahan baku, mungkin secara jangka panjang akan menguntungkan pedagang karena dari kartu ucapan tersebut dapat digunakan pelanggan sebagai hiasan dan keunikan dari setiap pedagang di Bakorwil II Jawa Timur. 
c. Pengaruh $Y$ terhadap $Z$, jika nilai $Y<0,05$ dinyatakan signifikan, tetapi setelah dilakukan pengujian didapatkan hasil tidak signifikan pada atribut (Y) Perusahaan mampu menjual dengan keunggulan harga yang lebih murah tetapi tidak mampu memberi pengaruh signifikan terhadap atribut (Z) Perusahaan memiliki target jumlah total penjualan lebih besar dibandingkan periode tahun sebelumnya, dikarenakan harga murah yang akan diberlakukan oleh industri kecil makanan tersebut tidak mampu memberikan keuntungan karena diarea Bakorwill II Jawa Timur, harga - harga makanan yang dijual sudah memiliki harga yang sangat murah dibanding dengan pesaingnya serta jika dimurahkan lagi belum tentu mampu mencapai target penjualan lebih baik dari tahun sebelumnya.

d. Pengaruh $\mathrm{X}$ melalui $\mathrm{Y}$ terhadap $\mathrm{Z}$ yaitu dalam proses mengetahui pengaruh langsung yang diberikan atribut (X1.1) Perusahaan mampu dengan cepat melayani pelanggan secara individual terhadap atribut $(Z)$ Perusahaan memiliki target jumlah total penjualan lebih besar dibandingkan periode tahun sebelumnya sebesar 0,543 maka sudah melampauhi 50\% dalam memberikan pelayanan yang cepat dan tepat untuk mengejar target penjualan agar lebih baik dari tahun sebelumnya. Kemudian pengaruh tidak langsung yang diberikan (X1.1) Perusahaan mampu dengan cepat melayani pelanggan secara individual melalui (Y) Perusahaan mampu menjual dengan keunggulan harga yang lebih murah terhadap atribut $(Z)$ Perusahaan memiliki target jumlah total penjualan lebih besar dibandingkan periode tahun sebelumnya proses perhitungan dengan cara perkalian antara atribut beta $(\mathrm{X} 1.1)$ terhadap $(\mathrm{Y})$ dikalikan dengan atribut beta $(\mathrm{Y})$ terhadap $(\mathrm{Z})$ sebagai berikut :

\section{Pengaruh tidak langsung $=0,461 \times 0,019$}

\section{Pengaruh tidak langsung $=0,008759$}

Dari perhitungan diatas, pengaruh secara tidak langsung yang diberikan sebesar 0,008759 dari Perusahaan mampu dengan cepat melayani pelanggan secara individual melalui (Y) Perusahaan mampu menjual dengan keunggulan harga yang lebih murah terhadap atribut $(Z)$ Perusahaan memiliki target jumlah total penjualan lebih besar dibandingkan periode tahun sebelumnya. Maka, pemberian pengaruh 
total pada atribut (X1.1) terhadap (Z) merupakan penjumlahan dari pengaruh langsung ditambah dengan pengaruh tidak langsung dengan rumus sebagai berikut

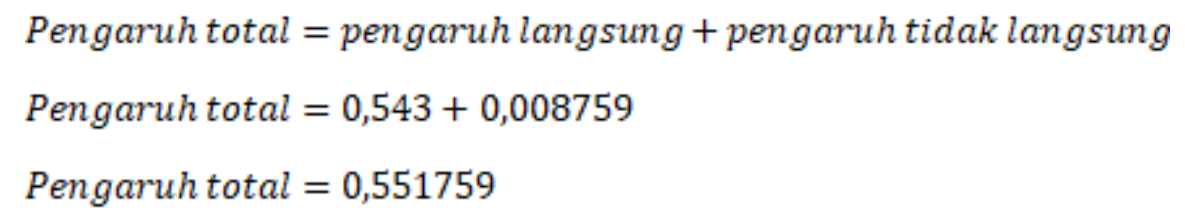

Maka, pengaruh total yang diberikan sebesar 0,551759. Dalam hal ini, pengaruh langsung memiliki nilai sebesar 0,543 sedangkan pengaruh tidak langsung lebih kecil yaitu sebesar 0,008759. Jadi, atribut (X1.1) memberi pengaruh secara langsung lebih besar dari pada pengaruh tidak langsung melalui (Y) terhadap (Z).

\section{KESIMPULAN}

Customer Relationship Management mampu memberikan pengaruh terhadap kinerja pemasaran tanpa melalui keunggulan bersaing dengan bukti pada path analysis nilai pengaruh total yaitu pada pengaruh langsung tanpa melalui keunggulan bersaing bernilai 0,543 yang artinya pengaruh langsung lebih besar dari pada melalui keunggulan bersaing yang bernilai 0,008759. Maka, dalam hal ini customer relationship management akan lebih bekerja maksimum jika keunggulan bersaing tidak diikutkan dalam peningkatan kinerja pemasaran.

Pada penelitian selanjutnya, alangkah baiknya ada penambahan atribut pada tiap variabel untuk mendapatkan hasil penelitian yang lebih komplek dan penelitian ini dapat dilanjutkan dengan pengembangan metode yang lain

\section{DAFTAR PUSTAKA}

Deitiana, T. (2011). Pengaruh Rasio Keuangan, Pertumbuhan Penjualan Dan Dividen Terhadap Harga Saham. Jurnal Bisnis Dan Akuntansi.

Djunaedi, D. (2016). Pengaruh Corporate Social Responsibility (CSR), dan Kualitas Produk Terhadap, Citra Bank dan Keputusan Menabung di BNI Syariah Kota Kediri. JMM17, 3(02).

Drucker, P. (2012). Management. Management. https:/ / doi.org/10.4324/9780080939063

Finnegan, D. J., \& Currie, W. L. (2010). A multi-layered approach to CRM implementation: An integration perspective. European Management Journal. Pengaruh Customer Relationship Management Terhadap Keunggulan Bersaing Dalam Meningkatkan Kinerja Pemasaran Usaha Kecil Industri Makanan Di Bakorwil II Jawa Timur 
https:/ / doi.org/10.1016/j.emj.2009.04.010

Heras, M. A., \& Dröge, H. (2009). Exploring Innovation Measurement Approaches in the Service Sector: Insights from the Hospitality Industry. Performance Measurment Association.

Hermuningsih, S. (2012). PENGARUH PROFITABILITAS, SIZE TERHADAP NILAI PERUSAHAAN DENGAN SRUKTUR MODAL SEBAGAI VARIABEL INTERVENING. Jurnal Siasat Bisnis. https:/ / doi.org/10.20885/jsb.vol16.iss2.art8

Holmbeck, G. N. (1997). Toward terminological, conceptual, and statistical clarity in the study of mediators and moderators: Examples from the child-clinical and pediatric psychology literatures. Journal of Consulting and Clinical Psychology. https:/ / doi.org/10.1037/0022-006X.65.4.599

Kaplan, R. S. (2009). Conceptual Foundations of the Balanced Scorecard. Handbooks of Management Accounting Research. https:// doi.org/10.1016/S1751-3243(07)030039

Komari, A. (2016). Strategi Pemasaran Produk Indosat M3 di Kota Kediri Berdasarkan Analisis SWOT, 3(2).

Kurniawan, D., Semuel, H., \& Japarianto, E. (2013). Analisis penerimaan nasabah terhadap layanan mobile banking dengan menggunakan pendekatan technology acceptance model dan theory of reasoned action. Jurnal Manajemen Pemasaran.

Laely, N. (2016). Analisis Pengaruh Kepercayaan dan Harga Terhadap Loyalitas Pelanggan Dimediasi Kepuasan Pada PT. Telkomsel di Kota Kediri. Ilmu Ekonomi \& Manajemen, 3(2), 61-74.

Musay, F. (2013). PENGARUH BRAND IMAGE TERHADAP KEPUTUSAN PEMBELIAN (SURVEI PADA KONSUMEN KFC KAWI MALANG). Jurnal Administrasi Bisnis.

Ogi, I., Massie, J., \& Lapian, A. (2016). PENGARUH ORIENTASI PASAR DAN INOVASI PRODUK TERHADAP KINERJA PEMASARAN PADA PT. BPR PRISMA DANA AMURANG. Jurnal Riset Ekonomi, Manajemen, Bisnis Dan Pengaruh Customer Relationship Management Terhadap Keunggulan Bersaing Dalam Meningkatkan Kinerja Pemasaran Usaha Kecil Industri Makanan Di Bakorwil II Jawa Timur 
Akuntansi.

Panjaitan, H., \& Djunaedi, D. (2017). Product Advantage , Customer Relationship Marketing, and Service Quality on Customer Satisfaction of Bank Syariah Mandiri in Surabaya. International Review of Management and Marketing, 7(4), 122130.

PARVATIYAR, A., \& Sheth, K. (2001). Customer Relationship Management: Emerging Practice, Process, and Discipline. Journal of Economic E Social Research.

Putri, I., \& Wirasedana, I. (2015). ANALISIS PERBANDINGAN PENILAIAN KINERJA BPR DENGAN PENDEKATAN BALANCED SCORECARD. E-Jurnal Akuntansi.

Riduwan, \& Kuncoro, E. A. (2008). Cara Menggunakan dan Memaknai Path Analysis (Analisis Jalur). Bandung: Alfabeta.

Safi'i, I. (2018). Klasifikasi Atribut Pelayanan Mobile Banking dengan Kano Model Berdasarkan Dimensi E-Servqual. Jurnal Sistem Dan Manajemen Industri, 2(2), 77. https:/ / doi.org/10.30656/jsmi.v2i2.696

Salim, O. C., Sudharma, N. I., Kusumaratna, R. K., \& Hidayat, A. (2016). Validitas dan reliabilitas World Health Organization Quality of Life-BREF untuk mengukur kualitas hidup lanjut usia. Universa Medicina.

Sheth, J., Parvatiyar, A., \& Berry, L. L. (2014). Relationship Marketing of Services: Growing Interest, Emerging Perspectives. In Handbook of Relationship Marketing. https:/ / doi.org/10.4135/9781452231310.n6

Smith, J. B., \& Colgate, M. (2007). Customer value creation: A practical framework. Journal of Marketing Theory and Practice. https://doi.org/10.2753/MTP10696679150101

Stanton, P., \& Stanton, J. (2002). Corporate annual reports: Research perspectives used. Accounting, Auditing $\mathcal{E}$ Accountability Journal. https:/ / doi.org/10.1108/09513570210440568 
Stonehouse, G., \& Snowdon, B. (2007). Competitive advantage revisited Michael Porter on strategy and competitiveness. Journal of Management Inquiry. https:/ / doi.org/10.1177/1056492607306333

Trang, I., Tewal, B., \& Tangkuman, K. (2015). PENILAIAN KINERJA, REWARD, DAN PUNISHMENT TERHADAP KINERJA KARYAWAN PADA PT. PERTAMINA (PERSERO) CABANG PEMASARAN SULUTTENGGO. Jurnal Riset Ekonomi, Manajemen, Bisnis Dan Akuntansi.

Wensley, R. (2010). Marketing strategy. In Marketing Theory: A Student Text. https:// doi.org/10.4135/9781446280096.n10

Williamson, O. E., Argyres, N., Mayer, K. K. J., Dorneles, T. M., Binotto, E., HolgadoSilva, H. C. H. C., ... BARDIN, L. (2016). CAPACIDADES DINÂMICAS COMO DIFERENCIAL ESTRATÉGICO PARA A SUSTENTABILIDADE. Journal of Business Research. https:/ / doi.org/10.1016/j.technovation.2012.01.004 